\title{
SPORTS ACTIVITY AND HIP, KNEE, SHOULDER AND INTERVERTEBRAL DISC ARTHROPLASTIES
}

\section{PRÁTICA DESPORTIVA E ARTROPLASTIA DE QUADRIL, JOELHO, OMBRO E DISCO INTERVERTEBRAL}

\author{
Diogo Lino Moura ${ }^{1,2}$, Fernando Pereira Fonseca ${ }^{1,2}$ \\ 1. Department of Orthopedics of the Centro Hospitalar e Universitário de Coimbra, Coimbra, Portugal. \\ 2. Faculty of Medicine of the University of Coimbra, Coimbra, Portugal.
}

\section{ABSTRACT}

The success of joint replacement surgery has been responsible for raising patients' expectations regarding the procedure. Many of these procedures are currently designed not only to relive the pain caused by arthrosis, but also to enable patients to achieve functional recovery and to engage in some degree of physical activity and sports. However, as physical exercise causes an increase in forces exercised through the articular prosthesis, it can be an important risk factor for its early failure. Scientific literature on sports after arthroplasty is limited to small-scale retrospective studies with shortterm follow-up, which are mostly insufficient to evaluate articular prosthesis durability. This article presents a review of the literature on sports in the context of hip, knee, shoulder and intervertebral disc arthroplasty, and puts forward general recommendations based on the current scientific evidence. Systematic Review, Level of Evidence III.

Keywords: Sports. Arthroplasty. Prostheses and implants. Hip.

\section{RESUMO}

O sucesso da artroplastia tem sido responsável pelo aumento das expectativas dos pacientes, sendo que, atualmente, muitos pretendem não apenas o alívio da dor causada pela artrose, mas também a recuperação funcional e praticar algum grau de atividade física e esportiva. No entanto, a prática de exercício físico, ao provocar um aumento das forças exercidas através da prótese articular, pode ser um importante fator de risco para a falha precoce. A literatura científica sobre esportes depois de artroplastia é limitada a pequenos estudos retrospectivos com pouco tempo de acompanhamento, na maioria insuficiente para a avaliação da duração da prótese articular. Este artigo apresenta uma revisão da literatura sobre prática desportiva no contexto de artroplastia do quadril, joelho, ombro e isco intervertebral e propõe recomendações gerais com base na evidência científica atual. Nível de Evidência III, Revisão Sistemática/Atualização.

Descritores: Esportes. Artroplastia. Próteses e Implantes. Quadril.

Citation: Moura DL, Fonseca FP. Sports activity and hip, knee, shoulder and intervertebral disc arthroplasties. Acta Ortop Bras. [online]. 2018;26(5):350-5. Available from URL: http://www.scielo.br/aob.

\section{INTRODUCTION}

Prosthetic joint replacement is among the most successful types of surgery in medical practice. According to Learmonth et al., total hip arthroplasty is the surgery of the century. ${ }^{1,2}$ The benefits of replacing a joint in an advanced stage of degeneration, particularly of the hip, knee, and shoulder, have been clearly demonstrated in terms of pain relief, improvement of function, correction of deformities, and improvement of quality of life., ${ }^{1,3,4}$ An aging population with higher functional requirements and lower tolerance to joint symptomatology requires joint replacement at a younger age and at less advanced stages of joint degeneration. These factors have been responsible for the worldwide increase in joint replacement surgery. ${ }^{1,4}$

\section{METHODS}

A search of the scientific literature on the association between sports and arthroplasty of the hip, knee, and shoulder, as well as intervertebral disk surgery, was performed using the PubMed/Medline database. The search focused on the following terms: "Arthroplasty", "Joint Replacement", "Sports" and "Physical exercise", yielding 76 articles. The inclusion criteria included original and review articles published in English in peer-reviewed journals, yielding 38 studies.

\section{Arthroplasty and exercise}

The effects of exercise on health are well known, with physical and mental benefits in all age groups. ${ }^{1,5}$ Given the success of arthroplastic surgery, patient expectations have increased, and many desire not only symptomatic relief of osteoarthritis pain, but also functional recovery, seeking to overcome the limitations caused by osteoarthritis and even to perform some degree of physical and sports activity. ${ }^{1,4}$ Some patients aim to return to a sport that they have been prevented from practicing due to degenerative osteoarthritis. ${ }^{6}$ The current scientific literature on sports after arthroplasty is limited to small retrospective studies with little follow-up time, mostly

All authors declare no potential conflict of interest related to this article. 
insufficient for assessment of the longevity of a joint prosthesis. ${ }^{1}$ Current total hip and knee prostheses (Figure 1) have a mean longevity of more than $90 \%$ at $10-20$ years after implantation; therefore, it is assumed that the minimum follow-up time for assessment of the longevity of an arthroplastic procedure is 10 years, at which point complications begin to appear. ${ }^{7,8,9,10}$

Physical exercise induces an increase in the forces exerted through the prosthesis, and can be an important risk factor for early failure. A high level of physical activity increases the risk of stress and wear between the prosthesis components and the prosthesis-bone interface, leading to early loosening and prosthesis instability. Physical exercise and decreased proprioception and pain are protective of the artificial joint, and are also responsible for an increased risk of traumatic lesions in a new joint. ${ }^{1,4-12}$ According to a Swedish registry that analyzed 92,675 hip arthroplasties and 30,003 knee arthroplasties, the 10-year surgical revision rates were significantly higher in patients aged less than 55 and 65 years (20\% and $18 \%$, respectively) than in older patients $(5 \%$ and $6 \%$, respectively), which may be attributable to a higher level of activity in younger patients. ${ }^{13,14}$ There is also some evidence that physical inactivity increases the risk of early loosening (in less than 10 years) due to osteopenia and insufficient osseointegration of noncemented prostheses, whereas increased physical activity increases the risk of component wear (usually polyethylene) and delayed loosening (over 10 years), caused by reactive osteolysis in association with particle release. ${ }^{5,8,15,16,17,18}$ Nevertheless, there is no scientific evidence for the type and level of activity that should be recommended or avoided after arthroplasty, with respect to the longevity of a new joint.1,10,14,19 Thus, the goal is to find a balance that guarantees the benefits of physical activity and at the same time does not reduce the longevity of the prosthesis.

\section{Hip arthroplasty and physical exercise}

The fixation technique and mechanical type and properties of the joint surfaces of a prosthesis are critical factors for longevity. ${ }^{10}$ As a general rule, noncemented fixation is preferable for young and active patients who play sports, as it allows dynamic osseointegration of the prosthesis and adaptation to functional demands, leading to lower rates of loosening than those with cemented prostheses..$^{10,20}$ In hip arthroplasty, despite extensive experience and good results

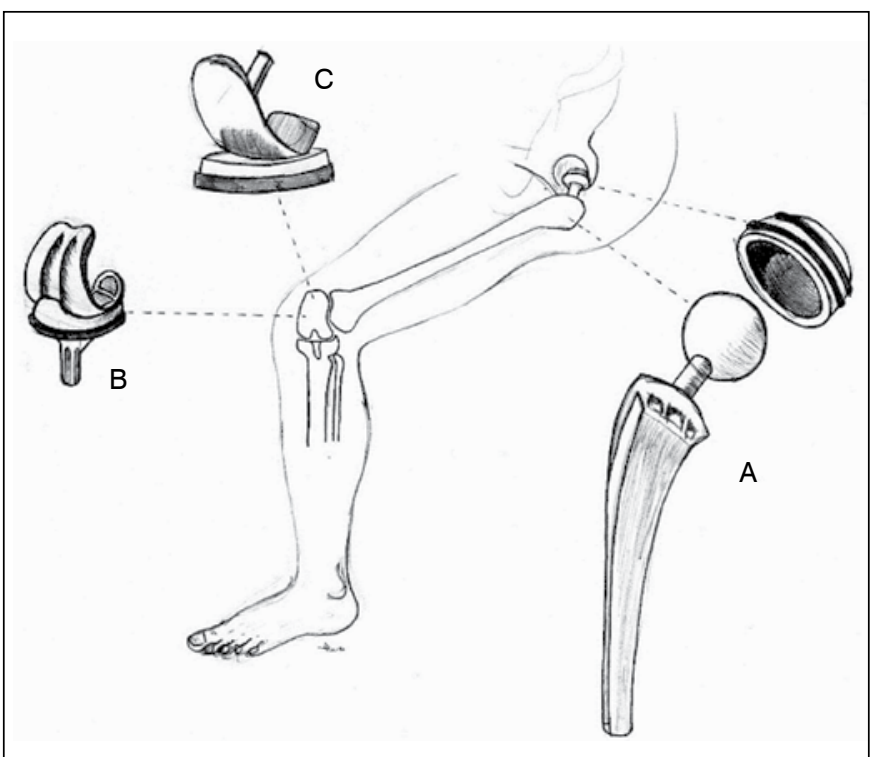

Figure 1. Total hip arthroplasty (A), total knee arthroplasty (B), unicompartmental knee arthroplasty (C) with metal-polyethylene joint combinations, ceramic and particularly ceramic-polyethylene combinations have been increasingly employed, mainly due to their lower susceptibility to wear and less particle release and osteolysis, leading to lower complication rates than with other materials. The higher strength of the latest generation of polyethylenes has also provided the orthopedic surgeon with greater confidence in the use of a total hip prosthesis in active patients. ${ }^{21-24}$ The rates of return to active sports after total hip arthroplasty range from $29 \%$ to $56 \%$ and are lower for high-impact sports. ${ }^{16,20,25}$ The main reasons for not returning to sports practice are pain, insufficient joint mobility, medical recommendation, and fear of damaging the replaced joint. ${ }^{26}$ Ritter and Meding ${ }^{25}$ and Dubs et al. ${ }^{16}$ demonstrated a decrease in sports practice from $78 \%$ in the preoperative period to $56 \%$ after hip arthroplasty. In contrast, Visuri and Honkanen ${ }^{27}$ reported an increase in recreational sports activity from 2 to $55 \%$ for walking, $7 \%$ to $29 \%$ for cycling, and $13 \%$ to $30 \%$ for swimming. Another study also found a slight increase (80\% to $83 \%)$ in recreational sports activity after total hip arthroplasty. ${ }^{28}$ Currently, most orthopedists advise patients who undergo arthroplasty of weight-bearing joints, particularly the hip and knee, to avoid high impact and contact sports, as they involve higher loads on the joint prosthesis and have a theoretically higher risk of component wear, loosening of the prosthesis, and traumatic injury., 4,5,10 Therefore, sports such as football, basketball, handball, tennis, volleyball, hockey, athletics, gymnastics, martial arts, and others are strongly discouraged, and sports with reduced impact such as cycling, swimming, water aerobics, dance, rowing, golf, and bowling, among others, are encouraged., ${ }^{1,4,5,18,19}$ Some authors allow the practice of high-impact exercise only on a recreational level with low intensity, and advise against competitive practice. ${ }^{5}$ In spite of this advice, some studies have demonstrated excellent functional results in patients with load-bearing prostheses in high-impact sports, even at a competitive level. ${ }^{16,29,31}$ Mont et al. ${ }^{29,30}$ demonstrated that all professional tennis players in their sample who underwent hip or knee arthroplasty (with 8 and 7 years of mean follow-up time, respectively) returned to competition. Surgical revision rates were $6 \%$ at 8 years for hip arthroplasty and 5 years for knee arthroplasty. Nevertheless, the duration of follow-up in these studies (less than 10 years) does not allow one to advise their practice, since it the duration insufficient to provide information about the status of the prosthesis. ${ }^{1,8}$ However, even with this limited scientific evidence, there has been growing acceptance of sports practice after arthroplasty among orthopedic doctors, probably due to the greater degree of function required by patients and the increased confidence among surgeons regarding surgical technique in joint reconstruction and innovation and improvements in the quality and durability of joint implants. ${ }^{1,10,18,19}$

\section{Knee arthroplasty and physical exercise}

In theory, noncemented fixation ensures dynamic osseointegration of a total knee prosthesis that is more favorable for sports practice, and the preservation of the posterior cruciate ligament allows higher levels of proprioception and consequently better functional results; however, these findings require validation, as results are similar with cemented fixation and techniques that sacrifice the posterior cruciate ligament. ${ }^{4,10} \mathrm{~A}$ study of 160 patients who underwent total knee arthroplasty, with a mean follow-up time of 5 years, revealed that $65 \%$ of those who practiced regular physical exercise before surgery and $35 \%$ of those who were inactive in the year prior to surgery returned to sports practice. ${ }^{32}$ The return rate was significantly higher for low-impact sports compared to high-impact sports (91\% vs $20 \%$ ). In a series of 144 total knee arthroplasties, Chatterji et al. found that $85 \%$ of patients practiced at least 1 recreational sport. ${ }^{33}$ Another study in golfers who underwent total knee arthroplasty reported 
that they all returned to the sport; however, after a minimum of 3 years, they reported significant pain during and after sports practice (16\% and $36 \%$, respectively), and signs of osteolysis were present in $53.7 \%$ of the prostheses. ${ }^{34}$ Osteolysis was more common in cemented prosthesis fixation, reaching a rate of $79.1 \%$, compared with $45 \%$ in the noncemented type. The hip and knee joints are weight-bearing; however the forces exerted on each are different, even at different times during the same sports activity. Unlike the hip prosthesis, in which the articular surface is always high, the congruence between the femoral and tibial components in knee prostheses is greatest in extension, and precarious at $40-60^{\circ}$ of knee flexion. This minimum contact between the joint surfaces in flexion is responsible for a substantial increase in contact stress, which favors destructive wear and delamination of the polyethylene insert. 5,35,36 The peak force on the prosthesis increases when the activity involves high-amplitude knee flexion. In theory, the manner in which these movements occur with greater frequency have more detrimental effects on the knee prosthesis, in particular greater risk of loosening of the tibial component., 7,37,38 Thus, patients with a total knee prosthesis should avoid, in addition to the sports already mentioned for weight-bearing joints, high-impact knee flexion activities, such as high-speed running, mountaineering, and slope walking, among others. ${ }^{5,7,37}$

The popularity of unicompartmental knee arthroplasty (Figure 1-C) has increased in recent years, emerging as an effective alternative to classic total arthroplasty (bi or tricompartmental) in patients with isolated osteoarthritis of medial or lateral femoral-tibial compartments. ${ }^{39,40}$ Its indications have led to increasing use at a very early age, resulting in higher functional levels and expectations in comparison with total knee arthroplasty. As such, its use has been increasing in individuals who play sports, despite limited evidence in this population. ${ }^{41,42,43}$ As with a total joint prosthesis, the unicompartmental prosthesis will also be subject to the injurious effect of excessive axial loads for any sports activities; however, the joint biomechanics are different. The preservation of both cruciate ligaments allows one to retain a large part of the physiological kinematics of the knee and maintain anteroposterior and rotational stability of the native joint, leading to less contact stress in these directions. Thus, in theory, these prostheses may be less likely to wear and loosening caused by excessive loads resulting from sports activities, thereby reducing the sports restrictions of their recipients. ${ }^{41,43-45}$ Furthermore, a mobile insert, often used in an attempt to replicate physiological meniscal function, ensures greater congruence between the prosthetic articular surfaces at various degrees of knee range of motion, and can also contribute to minimize shear forces that are potentially harmful to the new joint. ${ }^{46}$ In turn, greater articular anatomical preservation allows a higher level of proprioception in comparison with that for a total joint prosthesis, and may lead to more effective protection of the artificial joint and reduced risk of traumatic injuries. ${ }^{1,4}$ However, these theories remain to be proven and most orthopedists also apply the sports recommendations for total knee arthroplasty to unicompartmental arthroplasty. ${ }^{5,7,37,41}$ Walker et al ${ }^{42}$ retrospectively studied 101 patients who underwent medial unicompartmental arthroplasty, with a mean follow-up of $4.4 \pm 1.6$ years, and found a rate of return to sports practice of $93 \%$, mostly for low-impact sports activities. Specifically, $27 \%$ of the patients returned to physical activity in 1 month, 56\% returned in 3 months, $77 \%$ returned in 6 months, and the remaining 23\% needed longer than 6 months or remained inactive. The mean University of California at Los Angeles (UCLA) score improved significantly between preoperative and final assessments (3.3 \pm 1.5 vs. $6.8 \pm 1.5, p<0.001)$. Approximately $62 \%$ of patients played sports with a high physical activity score (defined as UCLA score $\geq 7$ ) after arthroplasty, with cycling (85\%), walking (57\%), and swimming (52\%) being the most practiced sports. Of this group, 29\% practiced high-impact activities, such as football (10\%), skiing (9\%), tennis (5\%), and athletics (5\%). Approximately $57 \%$ of the patients did not report any pain during sports practice, $17 \%$ had pain in the operated knee, and $26 \%$ had pain in other joints. Five revisions were performed for persistent pain; however, none was associated with sport practice. Naal et al. ${ }^{41}$ retrospectively studied 83 patients with unicompartmental arthroplasty over an average period of 18 months and found that the mean Knee Society Score improved from $129.9 \pm 24.8$ preoperatively to $186.9 \pm 18.3$ at the last evaluation, corresponding to a rate of return to sports practice of $94.8 \%$. Among these patients, $45.8 \%$ returned to physical activity in 3 months, $68.6 \%$ in 6 months, and the remaining $31.4 \%$ needed longer than 6 months. During sports practice, $47 \%$ of the patients did not report any pain, $28.9 \%$ had pain in the operated knee, and $26.5 \%$ had pain in other joints. Only 1 prosthesis showed signs of progressive radiolucency at the level of the femoral component; however, the patient was asymptomatic. Finally, a prospective study of 159 patients who underwent medial unicompartmental arthroplasty found a significant increase in the frequency of sports practice after arthroplasty (74\% versus $84 \%$ ) after a mean follow-up of $2 \pm 1.47$ years, with hiking, swimming, and cycling being the most practiced sports. ${ }^{43}$ Despite the satisfactory results reported in available studies and lack of an association between sports practice and complications in the neo-joint, the follow-up period is still insufficient to assess the longevity of the joint prosthesis., ${ }^{1,41,42,44}$

\section{Shoulder arthroplasty and physical exercise}

Arthroplasty of the glenohumeral joint (Figure 2) differs from hip and knee arthroplasty to the extent that is not a weight-bearing joint. Furthermore, the shoulder has the greatest range of motion in the human body but less congruency between its articular surfaces. As such, the main risks of arthroplastic surgery are early wear and loosening, particularly of the glenoid component, and joint instability. ${ }^{10}$ Although Poppen and Walker ${ }^{47}$ verified that the force perpendicular to the glenohumeral joint (abduction arm) could be close to that of body weight, Collins et al. ${ }^{48}$ concluded that the main cause of loosening of the glenoid component is eccentric load, which often occurs in some sports. As with hip and knee arthroplasty, noncemented fixation appears to have an advantage in young and active patients compared to that with cemented fixation. ${ }^{10}$ The ideal shoulder prosthesis for active patients depends on several factors, including the integrity of the rotator cuff. There has recently been an increase in indications and a growing trend toward the application of inverted glenohumeral arthroplasty compared with anatomic arthroplasty and hemi-arthroplasty. ${ }^{10,47-49}$ In theory,

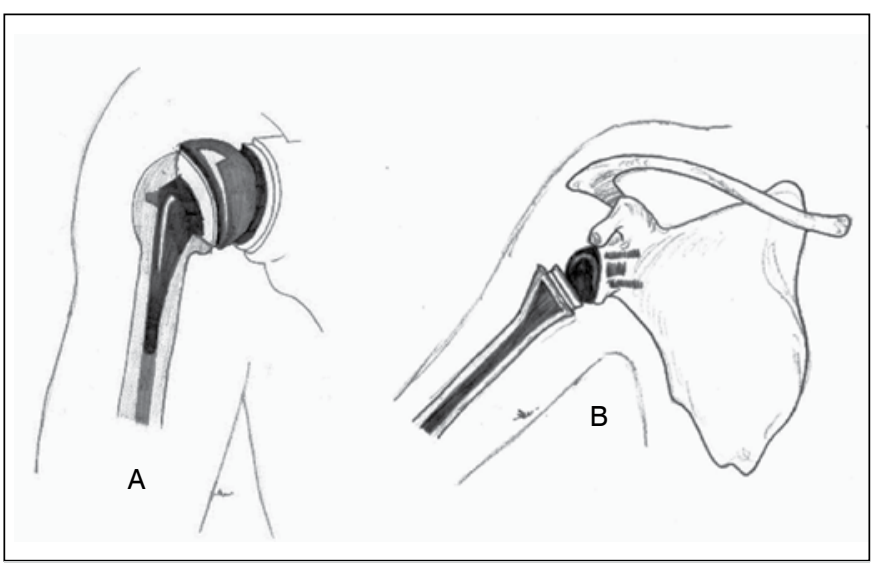

Figure 2. Anatomical glenohumeral arthroplasty (A) and reverse glenohumeral arthroplasty (B) 
contact sports and sports that require greater range of motion of the shoulder, such as weightlifting, handball, volleyball, tennis, hockey, golf, and gymnastics, among others, have increased risk of more pronounced wear, loosening, and injury of the arthroplastic shoulder, with ensuing need for a second early surgery, and should not be recommended. . $^{9,10,50,51}$ There are few studies on sports practice in patients with glenohumeral arthroplasty. Jensen and Rockwood ${ }^{50}$ showed that $96 \%$ of 24 patients in their study returned to recreational golf, the majority with better performance after arthroplastic shoulder replacement (anatomical and hemiarthroplasty). No significant differences were identified in the prevalence of radiographic signs of prosthetic loosening in comparison with those in a non-sports practicing control group during an average follow-up of 53.4 months. With an average follow-up of 3.7 years, a study of 75 athletes who underwent anatomical arthroplasty or hemiarthroplasty of the shoulder found that $71 \%$ showed improved sports performance, $50 \%$ showed increased frequency of sports activity in comparison with preoperative activity, and $19 \%$ did not return to sports practice after arthroplastic surgery of the shoulder. ${ }^{51}$ Only 4 of these patients underwent a second surgery, 3 of whom underwent arthroscopic debridement, with removal of the glenoid component secondary to loosening in 1 patient. Despite these figures, the authors do not guarantee that the rate of loosening will be lower, to the extent that many patients are initially asymptomatic, despite early radiographic signs of loosening. ${ }^{51,52}$ A prospective study of 100 patients who underwent total anatomical shoulder arthroplasty, with a mean follow-up of 2.8 years, found that only $6 \%$ of those who practiced sports previously did not return to physical exercise after arthroplastic surgery. ${ }^{53}$ Of the patients who returned to sports practice, $69.4 \%$ resumed the same modality and the same level of intensity, while the remaining patients changed to another sport, due to limitations related to the shoulder, particularly range of motion and strength. Another study of 67 patients (mean age 74.8 years) who practiced at least 1 sport preoperatively and who underwent inverted arthroplasty of the shoulder, with a mean follow-up time of 31.6 months, revealed that $85.5 \%$ returned to sports practice. Significantly fewer patients over the age of 70 years returned to a sport. ${ }^{49}$ Although these studies show that the frequency, level, and intensity of sports practice after shoulder arthroplasty, even in sports with high shoulder demands (for example, tennis and golf), are equivalent to those seen before the onset of osteoarthritis, none reported follow-up time and number of cases sufficient to assess the risk factors that affect the longevity of a joint prosthesis. ${ }^{49,50,51,52,53}$

\section{Disk arthroplasty and physical exercise}

Disk arthroplasty was developed to circumvent the loss of mobility of a vertebral segment and the risk of involvement of an adjacent disk that occurs in intersomatic arthrodesis as a treatment for advanced degenerative disk disease (Figure 3). With arthroplasty, the increased mobility and recreation of biomechanics, functionality, and distribution of loads closer to normal in the affected segment could in theory lead to lower rates of disk degeneration at adjacent levels. ${ }^{54}$ Disk arthroplasty should be applied in isolated symptomatic degenerative disk disease that does not respond to 6 months of conservative treatment, and generally only in patients without structural deformity or spinal instability, particularly interfacet osteoarthritis, and with acceptable bone quality. Given the high prevalence of contraindications associated with advancing age, the majority of arthroplasties are performed in young patients, many of whom have a need for increased activity and expectations of a high functional level. ${ }^{54-56}$ Although disk arthroplasties are still very new and medium- and long-term studies are limited, the promising results in the general population have led to growing popularity, with increasing use in younger patients who are more active and

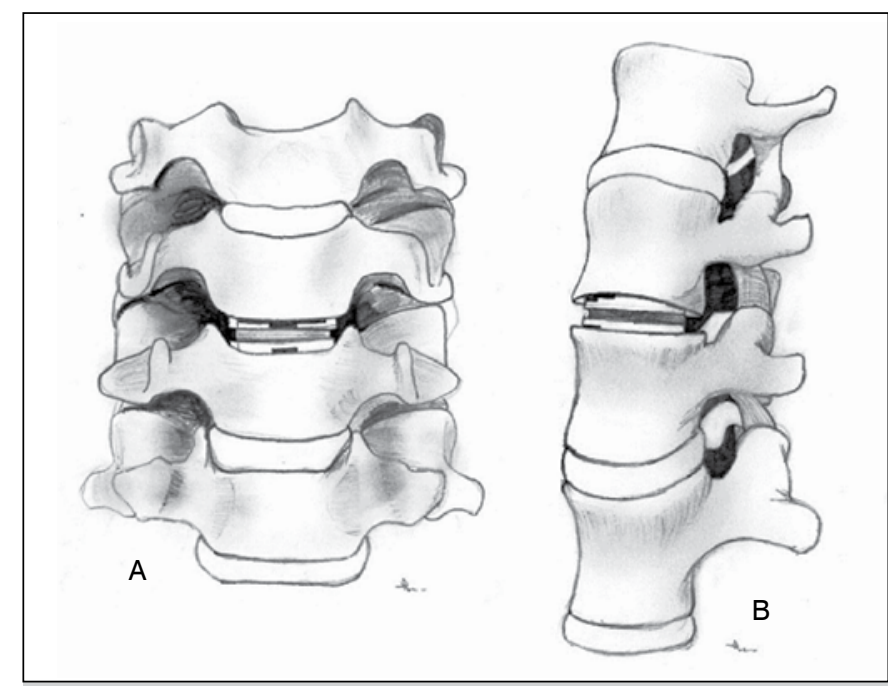

Figure 3. Cervical disk arthroplasty (A) and lumbar disk arthroplasty (B).

have higher functional expectations. ${ }^{56,57}$ Despite this trend, few studies have assessed the limitations and potential risks of these arthroplasties in sports practice; therefore, the level of permissible activity for patients with these implants to avoid compromising the longevity of the prosthesis remains unclear. ${ }^{56}$ During sports, an athlete can potentially experience excessive loads on an intervertebral prosthesis, which can lead to failure and early dysfunction. 1,56 In theory, high-impact contact sports and those with intensive activity may be associated with a higher risk of periprosthetic osteolysis, migration, and implant wear due to more frequently repeated axial and/or rotational loading on the column and the intervertebral implant, with consequent early failure of the prosthesis. ${ }^{55,56}$ Siepe et al. ${ }^{58}$ prospectively studied 39 practitioners of various contact sports or high-impact and professional level sports (mean age 39.8) who underwent lumbar disk arthroplasty, and verified significant symptomatic improvement in all patients after an average follow-up time of 26.3 months (average decrease of 5.7 on the visual analogue pain scale and $30 \%$ decrease in the Oswestry Disability Index). Return to sports practice was observed in $95 \%$ of the athletes, occurring within the first 3 months in $38.5 \%$ and at 3 and 6 months in $30.7 \%$ of the sample, with maximum sports performance reached after a mean time of 5.2 months after surgery. Approximately $85 \%$ of the sample showed significantly improved sports performance; however, $8 \%$ showed a reduced level of sports activity. The average frequency of sports practice increased $194 \%$, from 1.7 times per week in the preoperative period to 3.3 times in the postoperative period. One-third of the sample developed subsidence of the implant (migration of less than $5 \mathrm{~mm}$ ), with maintenance of function and always within the first 3 months after implantation; however, there was no association with sports practice. Progression of migration only occurred in 1 of these patients, but without functional impairment of the prosthesis and no radiographic signs of artificial disk wear. Tumialán et al. ${ }^{56}$ retrospectively studied soldiers, all of whom performed demanding or high-impact physical activity. Twelve soldiers underwent cervical disk arthroplasty and all returned to the same level of previous physical activity at an average time of 10.3 weeks. Another 12 men underwent lumbar disk arthroplasty and $83 \%$ returned to the previous activity level at an average time of 22.6 weeks. One patient left the military due to persistent symptoms, while another returned to physical activity with limitations. One of the patients with a cervical disk prosthesis developed osteolysis and needed implant removal and conversion to intersomatic arthrodesis, while another with a lumbar 
disk prosthesis developed an $\mathrm{S} 1$ radiculopathy, requiring surgical decompression. The mean follow-up times were only 12.2 months for cervical arthroplasty and 10.7 months for lumbar arthroplasty.

\section{Current General Recommendations}

The absence of prospective randomized studies that assessed the longevity of joint prostheses means that the current recommendations for sports practice in patients with arthroplasties are only based on the opinion of experts, and there is therefore a reduced level of scientific evidence. ${ }^{1,19}$ Case-by-case analysis and preoperative discussion of patient goals and expectations are needed to ensure that the type and technique of arthroplasty and rehabilitation conform to the final results. ${ }^{4,5}$ Patients should be encouraged to remain physically active, and the practice of low-impact sports in patients with prosthetic weight-bearing joints should be encouraged. ${ }^{4,5,10}$ Those who wish to practice a high-impact sport must understand the risks that are theoretically associated with that specific sport, particularly in terms of wear, loosening, instability and fractures in the region of the articular prosthesis, with consequent need for surgery or early revision. The decision to practice a sport must be made by the patient after weighing the risks and benefits. ${ }^{1,4,9,10}$ Before initiating sports practice, joint and trunk rehabilitation is recommended, in order to strengthen and protect the neo-joint, reduce the incidence of prosthetic failure, and prevent joint lesions. ${ }^{19,10}$ Additionally, these patients should have thorough clinical-radiological monitoring of the arthroplasty to enable detection and early intervention for complications that may arise. ${ }^{4}$

\section{ACKNOWLEDGMENTS}

Thanks to Ricardo Moura for his essential and excellent contribution.

AUTHORS' CONTRIBUTIONS: Each author made significant individual contributions to this manuscript. Both authors, DM (0000-0003-4037-2442) and FF (0000-0003-3572-2225), participated actively in the conception and development of this manuscript. DM contributed to the conception and design of the work and the acquisition, analysis and interpretation of data from the current scientific literature. He was also responsible for the drafting of its intellectual content. FF contributed significantly to the conception and design of the work. He was partly responsible for writing the manuscript, particularly for the section entitled "Current general recommendations", for the critical review of the intellectual content, and for the review and approval of its final version. *ORCID (Open Researcher and Contributor ID).

\section{REFERENCES}

1. Healy WL, Sharma S, Schwartz B, lorio R. Athletic activity after total joint arthroplasty. J Bone Joint Surg Am. 2008;90(10):2245-52

2. Learmonth ID, Young C, Rorabeck C. The operation of the century: total hip replacement. Lancet. 2007;370(9597):1508-19.

3. Laupacis A, Bourne R, Rorabeck C, Feeny D, Wong C, Tugwell P, et al. The effect of elective total hip replacement on health-related quality of life. J Bone Joint Surg Am. 1993;75(11):1619-26.

4. McGrory BJ, Stuart MJ, Sim FH. Participation in sports after hip and knee arthroplasty: review of literature and survey of surgeon preferences. Mayo Clin Proc. 1995;70(4):342-8

5. Kuster MS. Exercise recommendations after total joint replacement: a review of the current literature and proposal of scientifically based guidelines. Sports Med. 2002;32(7):433-45.

6. Weiss JM, Noble PC, Conditt MA, Kohl HW, Roberts S, Cook KF, et al. What functional activities are important to patients with knee replacements? Clin Orthop Relat Res. 2002;(404):172-88.

7. Dauty M, Letenneur J. [Sports participation after joint arthroplasty]. Ann Readapt Med Phys. 2007;50(9):709-15.

8. Kilgus DJ, Dorey FJ, Finerman GA, Amstutz HA. Patient activity, sport participation and impact loading on the durability of cemented total hip replacements. Clin Orth Relat Res. 1991;(269):25-31.

9. Vogel LA, Carotenuto G, Basti JJ, Levine WN. Physical activity after total joint arthroplasty. Sports Health. 2011;3(5):441-50.

10. Healy WL, lorio R, Lemos MJ. Athletic activity after joint replacement. Am J Sports Med. 2001;29(3):377-88

11. Schmalzried TP, Shepherd EF, Dorey FJ, Jackson WO, dela Rosa M, Fa'vae F, et al. The John Charnley Award. Wear is a function of use, not time. Clin Orthop Relat Res. 2000;(381):36-46.

12. Flugsrud GB, Nordsletten L, Espehaug B, Havelin LI, Meyer HE. The effect of middle-age body weight and physical activity on the risk of early revision hip arthroplasty: a cohort study of 1,535 individuals. Acta Orthop. 2007;78(1):99-107.

13. Malchau $H$, Herberts $P$, Ahnfelt $L$. Prognosis of total hip replacement in Sweden: follow-up of 92,675 operations performed 1978-1990. Acta Orthop Scand. 1993;64(5):497-506.

14. Knutson K, Lewold S, Robertsson O, Lidgren L. The Swedish knee arthroplasty register: a nation-wide study of 30,003 knees 1976-1992. Acta Orthop Scand. 1994:65(4):375-86

15. Gschwend N, Frei T, Morscher E, Nigg B, Loehr J. Alpine and cross-country skiing after total hip replacement: 2 cohorts of 50 patients each, one active, the other inactive in skiing, followed for 5-10 years. Acta Orthop Scand. 2000;71(3):243-9.

16. Dubs L, Gschwend N, Munzinger U. Sport after total hip arthroplasty. Arch Orthop Trauma Surg. 1983;101(3):161-9.

17. Jones DL, Cauley JA, Kriska AM, Wisniewski SR, Irrgang JJ, Heck DA, et al. Physical activity and risk of revision total knee arthroplasty in individuals with knee osteoarthritis: a matched case-control study. J Rheumatol. 2004;31(7):1384-90.
18. Swanson EA, Schmalzried TP, Dorey FJ. Activity recommendations after total hip and knee arthroplasty: a survey of the American Association for Hip and Knee Surgeons. J Arthroplasty. 2009;24(6 Suppl):120-6.

19. Klein GR, Levine BR, Hozack WJ, Strauss EJ, D'Antonio JA, Macaulay W, et al. Return to athletic activity after total hip arthroplasty. Consensus guidelines based on a survey of the Hip Society and American Association of Hip and Knee Surgeons. J Arthroplasty. 2007;22(2):171-5

20. Mallon WJ, Callaghan JJ. Total hip arthroplasty in active golfers. J Arthroplasty. 1992;7 Suppl:339-46.

21. Cash DJ, Khanduja V. The case for ceramic-on-polyethylene as the preferred bearing for a young adult hip replacement. Hip Int. 2014;24(5):421-7.

22. Urban JA, Garvin KL, Boese CK, Bryson L, Pedersen DR, Callaghan JJ, et al. Ceramic-on-polyethylene bearing surfaces in total hip arthroplasty. Seventeen to twenty-one-year results. J Bone Joint Surg Am. 2001;83-A(11):1688-94.

23. Meftah M, Klingenstein GG, Yun RJ, Ranawat AS, Ranawat CS. Long-term performance of ceramic and metal femoral heads on conventional polyethylene in young and active patients: a matched-pair analysis. J Bone Joint Surg Am. 2013;95(13):1193-7.

24. Affatato S, De Mattia JS, Bracco P, Pavoni E, Taddei P. Does cyclic stress and accelerated ageing influence the wear behavior of highly crosslinked polyethylene? J Mech Behav Biomed Mater. 2016;59:418-29.

25. Ritter MA, Meding JB. Total hip arthroplasty: can the patient play sport again? Orthopedics 1987;10(10): 1447-52.

26. Wylde V, Blom A, Dieppe P, Hewlett S, Learmonth I. Return to sport after joint replacement. J Bone Joint Surg Br. 2008;90(7):920-3.

27. Visuri T, Honkanen R. Total hip replacement: Its influence on spontaneous recreation exercise habits. Arch Phys Med Rehabil. 1980;61:325-8.

28. Chatterji U, Ashworth MJ, Lewis PL, Dobson PJ. Effect of total hip arthroplasty on recreational and sporting activity. ANZ J Surg. 2004;74(6):446-9.

29. Mont MA, LaPorte DM, Mullick T, Silberstein CE, Hungerford DS. Tennis after total hip arthroplasty. Am J Sports Med. 1999;27(1):60-4

30. Mont MA, Rajadhyaksha AD, Marxen JL, Silberstein CE, Hungerford DS. Tennis after total knee arthroplasty. Am J Sports Med. 2002;30(2):163-6.

31. Diduch DR, Insall JN, Scott WN, Scuderi GR, Font-Rodriguez D. Total knee replacement in young, active patients: long-term follow-up and functional outcome. J Bone Joint Surg Am. 1997;79(4):575-82.

32. Bradbury N, Borton D, Spoo G, Cross MJ. Participation in sports after total knee replacement. Am J Sports Med. 1998;26(4):530-5.

33. Chatterji U, Ashworth MJ, Lewis PL, Dobson PJ. Effect of total knee arthroplasty on recreational and sporting activity. ANZ J Surg. 2005;75(6):405-8.

34. Mallon WJ, Callaghan JJ. Total knee arthroplasty in active golfers. J Arthroplasty 1993;8(3):299-306.

35. Kuster MS, Horz S, Spalinger E, Stachwiak GW, Gachter A. The effects of conformity and load in total knee replacement. Clin Orthop Relat Res. 2000;(375):302-12.

36. Kuster MS, Wood GA, Stachowiak GW, Gachter A. Joint load considerations in total knee replacement. J Bone Joint Surg Br. 1997;79(1):109-13. 
37. Kuster MS, Spalinger E, Blanksby BA, Gachter A. Endurance sports after total knee replacement: a biomechanical investigation. Med Sci Sports Exerc. 2000;32(4):721-4.

38. Hilding MB, Lanshammar H, Ryd L. Knee joint loading and tibial component loosening: RSA and gait analysis in 45 osteoarthritic patients before and after TKA. J Bone Joint Surg Br. 1996;78(1):66-73.

39. Berend KR, Lombardi AV Jr. Mobile-bearing unicompartmental knee arthroplasty (UKA). Orthopedics. 2008;31(5 Suppl):S6-8.

40. Waldstein W, Kolbitsch P, Koller U, Boettner F, Windhager R. Sport and physica activity following unicompartmental knee arthroplasty: a systematic review. Knee Surg Sports Traumatol Arthrosc. 2017;25(3):717-28.

41. 41. Naal FD, Fischer M, Preuss A, Goldhahn J, von Knoch F, Preiss S, et al. Return to sports and recreational activity after unicompartmental knee arthroplasty. Am J Sports Med. 2007;35(10):1688-95.

42. Walker T, Streit J, Gotterbarm T, Bruckner T, Merle C, Streit MR. Sports, Physical Activity and Patient-Reported Outcomes After Medial Unicompartmental Knee Arthroplasty in Young Patients. J Arthroplasty. 2015;30(11):1911-6.

43. Jahnke A, Mende JK, Maier GS, Ahmed GA, Ishaque BA, Schmitt $\mathrm{H}$, et al. Sports activities before and after medial unicompartmental knee arthroplasty using the new Heidelberg Sports Activity Score. Int Orthop. 2015;39(3):449-54.

44. Fisher N, Agarwal M, Reuben SF, Johnson DS, Turner PG. Sporting and physical activity following Oxford medial unicompartmental knee arthroplasty. Knee. 2006;13(4):296-300.

45. Hernigou P, Deschamps G. Alignment influences wear in the knee after medial unicompartmental arthroplasty. Clin Orthop Relat Res. 2004;(423):161-5.

46. Kendrick BJ, Longino D, Pandit H, Svard U, Gill HS, Dodd CA, et al. Polyethylene wear in Oxford unicompartmental knee replacement: a retrieval study of 47 bearings. J Bone Joint Surg Br. 2010;92(3):367-73.

47. Poppen NK, Walker PS. Forces at the glenohumeral joint in abduction. Clin Orthop Relat Res. 1978;(135):165-70.
48. Collins D, Tencer A, Sidles J, Matsen F 3rd. Edge displacement and deformation of glenoid components in response to eccentric loading. The effect of preparation of the glenoid bone. J Bone Joint Surg Am. 1992;74(4):501-7.

49. Garcia GH, Taylor SA, DePalma BJ, Mahony GT, Grawe BM, Nguyen J, et al. Patient Activity Levels After Reverse Total Shoulder Arthroplasty: What Are Patients Doing? Am J Sports Med. 2015;43(11):2816-21.

50. Jensen KL, Rockwood CA Jr. Shoulder arthroplasty in recreational golfers. J Shoulder Elbow Surg. 1998;7(4):362-7.

51. McCarty EC, Marx RG, Maerz D, Altchek D, Warren RF. Sports participation after shoulder replacement surgery. Am J Sports Med. 2008;36(8):1577-81.

52. Gartsman GM, Roddey TS, Hammerman SM. Shoulder arthroplasty with or without resurfacing of the glenoid in patients who have osteoarthritis. J Bone Joint Surg Am. 2000;82(1):26-34.

53. Schumann K, Flury MP, Schwyzer HK, Simmen BR, Drerup S, Goldhahn J. Sports activity after anatomical total shoulder arthroplasty. Am J Sports Med 2010;38(10):2097-105.

54. Auerbach JD, Anakwenze OA, Milby AH, Lonner BS, Balderston RA. Segmental contribution toward total cervical range of motion: a comparison of cervical disk arthroplasty and fusion. Spine (Phila Pa 1976). 2011;36(25):E1593-9.

55. Büttner-Janz K, Guyer RD, Ohnmeiss DD. Indications for Lumbar Total Disk Replacement: Selecting the Right Patient with the Right Indication for the Right Total Disk. Int J Spine Surg. 2014;8:12.

56. Tumialán LM, Ponton RP, Garvin A, Gluf WM. Arthroplasty in the military: a preliminary experience with ProDisk-C and ProDisk-L. Neurosurg Focus. 2010;28(5):E18.

57. McAfee PC. The indications for lumbar and cervical disk replacement. Spine J. 2004:4(6 Suppl):177S-81S

58. Siepe CJ, Wiechert K, Khattab MF, Korge A, Mayer HM. Total lumbar disk replacement in athletes: clinical results, return to sport and athletic performance. Eur Spine J. 2007;16(7):1001-13 